\title{
Prenatal multivitamin supplementation increases birth weight
}

\author{
Müberra Namli Kalem ${ }^{1 *}$, Zeynep Kamalak², Nermin Kosus ${ }^{3}$, Aydin Kosus ${ }^{3}$, Ziya Kalem ${ }^{4}$
}

\author{
${ }^{1}$ Department of Obstetrics and Gynecology, Liv Hospital, Ankara, Turkey \\ ${ }^{2}$ Department of Obstetrics and Gynecology, Özel Buhara Hastanesi Palandöken, Erzurum, Turkey \\ ${ }^{3}$ Department of Obstetrics and Gynecology, Private Practice, Ankara, Turkey \\ ${ }^{4}$ Department of IVF, Gurgan Clinic, IVF and Women Health Center, Ankara, Turkey
}

Received: 23 March 2017

Accepted: 22 April 2017

\section{*Correspondence:}

Dr. Müberra Namli Kalem,

E-mail: muberranamli@ hotmail.com

Copyright: () the author(s), publisher and licensee Medip Academy. This is an open-access article distributed under the terms of the Creative Commons Attribution Non-Commercial License, which permits unrestricted non-commercial use, distribution, and reproduction in any medium, provided the original work is properly cited.

\begin{abstract}
Background: The aim of this study is to examine whether there is any positive impact of prenatal iron and vitamin supplementation on birth weight, and if this practice could be a cause of macrosomia.

Methods: A total of 1,838 term pregnant women were included in this study and were divided into four groups: iron group (women having only iron supplementation), vitamin (women using only multivitamins), vitamin+iron (women using both iron and multivitamin preparations), and control group (women having neither iron nor vitamin supplements). Statistical analysis was performed to compare age, gravida, parity, hemoglobin, BMI and birth weight. Groups were compared in terms of macrosomia and correlation analysis carried out between demographics and birth weight.

Results: The birth weight was significantly higher in the vitamin group and the vitamin+iron group than in the iron group and the control group. Vitamin supplementation increased the risk of macrosomia 3.9 times, while vitamin+iron usage increased the risk 4.8 times.

Conclusions: Uncontrolled use of multivitamins and/or iron supplements may increase tendency for fetal macrosomia. The use of multivitamins and/or iron supplements by pregnant women must take into account maternal age, maternal diet and maternal BMI. Our findings support a reduction in the unnecessary use of vitamin and iron supplements in pregnancy, and a reversal of the trend to start vitamin and iron supplementation without any control. The increasing prevalence of obesity and excessive weight in pregnant women should be a warning against the uncontrolled usage of vitamins and iron during pregnancy.
\end{abstract}

Keywords: Birth weight, Iron, Macrosomia, Prenatal vitamin supplementation

\section{INTRODUCTION}

Epidemiological studies have shown that nutrition during pregnancy influences fetal growth, fetal development and the risk of various diseases later in life, as well as the well-being of the mother. ${ }^{1,2}$ Multivitamin and iron supplements are major component of prenatal care, and have been shown to reduce the risk of low birth weight, although this effect may be mediated through gestational weight gain or by the prevention of anemia, which have impacts on pregnancy outcome and affects both the mother and the fetus. 3,4

The prevalence of anemia and micromineral-vitamin deficiencies in pregnant women differs considerably depending on their lifestyle and cultural and socioeconomic status. ${ }^{5}$ Previous controlled randomized studies have identified important improvements in pregnancy outcomes after the utilization of a supplemental diet. ${ }^{6,7}$ In some developed countries, over- 
dosages of micronutrients are common as a result of marketing strategies, while deficiencies are prevalent in the developing world. ${ }^{6}$

Between 20 and 30 percent of pregnant women suffer from at least one kind of vitamin deficiency. ${ }^{8}$ Malnourished women more likely to experience adverse pregnancy outcomes, such as growth-restricted babies, neural tube defects, pre-eclampsia and LBW, which can be prevented through good nutrition and the use of mineral and vitamin supplements. ${ }^{9}$ Multivitamin use during pregnancy is a key factor in the prophylaxis and management of nutritional deficiencies, although there are concerns related to excessive vitamin and iron consumption as a general vitamin and/or iron prophylaxis among pregnant women. ${ }^{10}$

Micronutrient and iron supplements are often recommended by physicians without consideration of the dietary intake or iron status of their patient. During pregnancy, an increased demand may become evident, however in non-deficient pregnant women, little is known about the effects of supplementation. Watson et al. ${ }^{11}$ studied 504 pregnant women to identify the relationship between birth weight and maternal dietary supplementation, revealing that dietary supplement usage was associated with increased birth weight, and is related most significantly with iron supplementation. Urbaniak T. et al. ${ }^{12}$ showed in their study that women taking folic acid and multivitamins before pregnancy increased the chance of having a neonate of higher body mass index.

There is an increasing concern related to the excessive use of vitamins and iron as a general vitamin and/or iron prophylaxis among pregnant women without consideration of their dietary intake or basal iron status. Since it has been shown in many studies that nutrition during pregnancy influences fetal growth and development, in this study we aimed to evaulate the role of multiple micronutrient supplementation and/or iron usage on birth weight, and risk of macrosomia.

\section{METHODS}

This retrospective study was conducted between April 2012 and August 2015 after obtaining approval from Turgut Özal University Hospital Ethics Committee, and was carried out in compliance with the principles of the Helsinki Declaration. The study included a total of 1,838 postpartum women who attended a public hospital and a university hospital for given birth and postnatal care during the study period. Informed consent was obtained from all patients about the study. We asked all participants, who have given birth healthy, single and term babies, to fill in a questionnaire during their routine post-partum control visit. Only patients that regularly used their prescribed iron and vitamin pills have been included into the study. Regular drug usage based on the given information by the patients, where the patients declared that they took their prescribed medication daily during the period that begun from the first prenatal visit, which had to be in the first eight weeks of pregnancy, to labor.

The patients' age, weight, height, parity, gravidity and previous mode of delivery were recorded, and they were asked for their pre-pregnancy weight and height. The patients' body mass indexes (BMI) were calculated using their pre-pregnancy height and weight in centimeters and kilograms respectively. On admission to the delivery ward, the total maternal weight gain during the pregnancy was recorded. Maternal parity was defined as previous births and stillbirths at 20 weeks of gestation or later, and this data was also included. All deliveries were completed at more than 38 completed weeks of gestation. The last menstrual period, the use of multivitamins, iron and folic acid were documented for the current pregnancy. Excluded from the study were women with multiple pregnancies, those with medical conditions such as hypertension, diabetes, peptic ulcers, renal disease, thyroid disorders and asthma; and those with obstetric pathologies such as preterm or prolonged pregnancies, intra-uterine growth retardation (IUGR) or placental abruption.

The data of a total 1,838 patients was analyzed, and the subjects were arranged into four groups: iron group (women having only iron supplementation), vitamin group (women using only multivitamins), vitamin and iron group (women using both iron and multivitamin preparations) and the control group (women having neither iron nor vitamin supplements during pregnancy). The patients in this study used supplemental tablets that contained multivitamins and various minerals with or without iron. All medications were contained folic acid 400 micrograms, oral iron tablets were contained $40 \mathrm{mg}$ elemental iron at least and multivitamin tablets (Elevit Pronatal/Elevit; Bayer, Istanbul, Turkey or Decavit Pronatal/Decavit; Kocak, Istanbul, Turkey) were contained various vitamin and mineral, with or without $60 \mathrm{mg}$ elemental iron.

The subjects were then grouped according to birth weight (more than 4500 grams and less than 4500 grams) and a statistical analysis was carried out to identify the most influential factors in the prediction of birth weight. The same analysis was made for cases in which the birth weight was more than 4000 grams and less than 4000 grams.

\section{Statistical analysis}

The SPSS 16.0 (The Statistical Package Program for the Social Sciences, SPSS Inc., United States) was used for the statistical analysis. Data was controlled in terms of conformity to normal distribution using the Shapiro-Wilk test, which identified that the data did not comply with normal distribution. The median (minimum-maximum) were used for continual variables and the categorical variables were expressed as a number and a percentage. 
A Kruskal Wallis test was used to compare three or more free groups, and a Mann-Whitney test was used for a double comparison, which determined the significant differences in the data. Chi-square tests were conducted to test the distribution between categorical variables, and a Lineer regression and a Spearman Correlation analysis were used to evaluate the factors predicting birth weight. To determine the factors that could affect babies between $4500 \mathrm{gr}$ and $4000 \mathrm{gr}$, a logistic regression analysis was used, with $\mathrm{P}<0.05$ being considered significant. The parameters which can affect the birth weight estimation without any cut-off, have been analyzed by Lineer regression. Logistic regression was used to evaluate the parameters to estimate the weight of the babies above the cut-off values 4500gr and 4000gr. Backward LR method was used for regression analysis.

\section{RESULTS}

Data on a total of 1,838 patients was analyzed, with the subjects arranged into four groups: Iron group $(n=452)$, vitamin group $(n=366)$, vitamin+iron group $(n=478)$ and control group $(\mathrm{n}=542)$. The distribution of age, gravidity, parity and BMI $(\mathrm{kg} / \mathrm{m} 2)$ was similar in all groups, and there was no difference in demographic parameters between the groups $(\mathrm{p}>0.05)$. The demographic features of the subjects are presented in Table 1.

Table 1: Demographic and clinical features of groups expressed as mean (min-max).

\begin{tabular}{|llllll|}
\hline & Control & Iron & Vitamin & \multicolumn{2}{c|}{ Vitamin+Tron } \\
& $(\mathrm{n}=542)$ & $(\mathrm{n}=452)$ & $(\mathrm{n}=366)$ & $278)$ & \\
\hline Age (years) & $28(18-38)$ & $27.5(18-45)$ & $27(19-46)$ & $26(18-40)$ & 0.361 \\
\hline Gravidy $(\mathrm{n})$ & $2(1-6)$ & $2(1-8)$ & $2(1-7)$ & $2(1-8)$ & 0.128 \\
\hline Parity $(\mathrm{n})$ & $2(1-5)$ & $2(1-6)$ & $2(1-5)$ & $2(1-6)$ & 0.334 \\
\hline BMI $\left(\mathrm{kg} / \mathrm{m}^{2}\right)$ & $27.34(21.72-35.94)$ & $27.34(20.20-42.06)$ & $26.71(17.19-36.33)$ & $27.61(16.53-39.06)$ & 0.529 \\
\hline Birth weight $(\mathrm{g})$ & $3100(2500-4000)$ & $3175(2700-4500)$ & $3300(2200-4750)$ & $3300(1700-5000)$ & $<0.001 *$ \\
\hline Hb $(\mathrm{g} / \mathrm{dL})$ & $12(8-15)$ & $12(10-14)$ & $12(9-15)$ & $12(7-14)$ & 0.317 \\
\hline
\end{tabular}

* Statistically significant difference between control and iron groups versus vitamin and vitamin+iron groups.

A comparison of the groups in terms of birth weight were showed that the birth weight was significantly higher in the vitamin group and vitamin+iron group than in the iron group and the control group $(\mathrm{p}<0.001, \mathrm{p}<0.001)$.

The birth weight was higher in vitamin+iron group than vitamin group, although not to a statistically significant degree $(p>0.05)$. When the groups were compared in terms of macrosomia (birth weight over 4500 grams), a statistically significant difference was identified between the vitamin+iron group and the control group $(\mathrm{p}=0.010)$, while there was no difference between the other groups ( $p>0.05)$. A comparison of the cases with babies weighing more and less than 4000 grams resulted in a significantly higher number of cases over $4000 \mathrm{gr}$ in the vitamin and vitamin+iron groups than in the control group and the iron group $(\mathrm{p}<0.001, \mathrm{p}<0.001)$. The macrosomic infant ratio was higher in the vitamin+iron group than in the only vitamin group, but difference did not reach statistical significance $(\mathrm{p}=0.144)$ (Table 2$)$.

Table 2: Comparison of groups in terms of macrosomia.

\begin{tabular}{|c|c|c|c|c|c|c|c|c|}
\hline & & $<4500$ & $\geq 4500$ & $<4000$ & $\geq 4000$ & $<2500$ & $\geq 2500$ & \\
\hline & & $n=1829$ & $\mathbf{n}=9$ & $n=1770$ & $n=68$ & $\mathrm{n}=32$ & $n=1806$ & p \\
\hline \multirow[t]{2}{*}{ Control } & $\mathrm{n}$ & 542 & 0 & 539 & 3 & 17 & 525 & \\
\hline & $\%$ & 100.0 & 0.0 & 99.4 & 0.6 & 3.1 & 96.9 & $0.017 *$ \\
\hline \multirow[t]{2}{*}{ Iron } & $\mathrm{n}$ & 451 & 1 & 448 & 4 & 7 & 445 & \\
\hline & $\%$ & 99.8 & 0.2 & 99.1 & 0.9 & 1.5 & 98.5 & \\
\hline \multirow[t]{2}{*}{ Vit. } & $\mathrm{n}$ & 364 & 2 & 344 & 22 & 5 & 361 & \\
\hline & $\%$ & 99.5 & 0.5 & 94.0 & 6.0 & 1.4 & 98.6 & $<0.001 f$ \\
\hline \multirow[t]{2}{*}{ Vit+Iron } & $\mathrm{n}$ & 472 & 6 & 439 & 39 & 3 & 475 & \\
\hline & $\%$ & 98.7 & 1.3 & 91.8 & 8.2 & 0.6 & 99.4 & $0.005 q$ \\
\hline
\end{tabular}

* significant difference between vitamin+iron group and control group in terms of birth weight below and above $4500 \mathrm{~g}$. $f$ significant difference between vitamin and vitamin+iron groups versus control and iron groups in terms of birth weight below and above $4000 \mathrm{~g}$. \{ significant difference between vitamin+iron group and control group in terms of birth weight below and above $2500 \mathrm{~g}$. 
A correlation analysis revealed a minimal positive correlation between birth weight versus gravidity, parity and maternal BMI ( $>0.05)$ (Table 3), while the Lineer regression analysis revealed that for the prediction of the birth weight, maternal BMI was the most accurate $(p<0.001)$. Maternal BMI was also more effectual for the prediction of macrosomia (birth weight of more than 4500 grams), according to a logistic regression analysis $(\mathrm{p}=0.002)$. Although vitamin supplementation increased the risk of macrosomia by 3.9 , vitamin+iron usage increased the risk 4.8 times, although these figures did not reach statistical significance. $(p=0.274$ and $p=0.174$, respectively) (Table 4).

Table 3: The correlation analysis between demographic parameters and birth weight.

\begin{tabular}{|llllllll|} 
& & Age & Gravida & Parity & BW & Hb & BMI \\
\hline Age & Rho & & $0.548^{*}$ & $0.550^{*}$ & 0.043 & 0.042 & $0.089^{*}$ \\
& $\mathrm{p}$ & & $<0.001$ & $<0.001$ & 0.063 & 0.428 & $<0.001$ \\
\hline Gravida & Rho & $0.548^{*}$ & & $0.889^{*}$ & $0.081^{*}$ & 0.040 & $0.083^{*}$ \\
\hline & $\mathrm{p}$ & $<0.001$ & & $<0.001$ & 0.001 & 0.459 & $<0.001$ \\
\hline Parity & Rho & $0.550^{*}$ & $0.889^{*}$ & & $0.060^{*}$ & 0.035 & $0.111^{* *}$ \\
\hline & $\mathrm{p}$ & $<0.001$ & $<0.001$ & & 0.010 & 0.518 & $<0.001$ \\
\hline BW & Rho & 0.043 & $0.081^{*}$ & $0.060^{*}$ & & -0.023 & $0.065^{*}$ \\
\hline & $\mathrm{p}$ & 0.063 & 0.001 & 0.010 & & 0.669 & 0.006 \\
\hline Hb & Rho & 0.042 & 0.040 & 0.035 & -0.023 & -0.006 \\
\hline & $\mathrm{p}$ & 0.428 & 0.459 & 0.518 & 0.669 & 0.907 \\
\hline BMI & Rho & $0.089^{*}$ & $0.083^{*}$ & $0.111^{*}$ & $0.065^{*}$ & -0.006 & 0.907 \\
\hline
\end{tabular}

* Correlation is significant at the 0.05 level. BW: Birth weight, Hb: Hemoglobin, BMI: Body-mass index.

Table 4: Results of logistic regression analysis.

\begin{tabular}{|c|c|c|c|c|}
\hline & B & SE & p & $\operatorname{Exp}(B)$ \\
\hline \multicolumn{5}{|l|}{$\geq 4500 \mathrm{~g}$} \\
\hline BMI & 0.274 & 0.088 & 0.002 & 1.315 \\
\hline Constant & $\begin{array}{l}- \\
12.066\end{array}$ & 2.840 & $<0.001$ & 0.000 \\
\hline Vitamin & 1.381 & 1.264 & 0.274 & 3.980 \\
\hline Vitamin+Iron & 1.573 & 1.157 & 0.174 & 4.820 \\
\hline Iron & 16.500 & 4.635 & 0.997 & 1.465 \\
\hline \multicolumn{5}{|l|}{$\geq 4000 \mathrm{~g}$} \\
\hline BMI & 0.350 & 0.076 & $<0.001$ & 1.419 \\
\hline Constant & $\begin{array}{l}- \\
14.977\end{array}$ & 2.730 & $<0.001$ & 0.000 \\
\hline Vitamin & 1.900 & 0.944 & 0.044 & 6.686 \\
\hline Vitamin+Iron & 1.483 & 0.890 & 0.096 & 4.405 \\
\hline Iron & -0.675 & 1.507 & 0.654 & 0.509 \\
\hline \multicolumn{5}{|l|}{$<2500$} \\
\hline BMI & -0.056 & 0.061 & 0.357 & 0.945 \\
\hline Constant & 5.058 & 0.579 & $<0.001$ & 157.333 \\
\hline Vitamin & -0.540 & 0.497 & 0.277 & 0.583 \\
\hline Vitamin+Iron & -1.213 & 0.610 & 0.047 & 0.297 \\
\hline Iron & -0.667 & 0.458 & 0.145 & 0.513 \\
\hline
\end{tabular}

B: Regression coefficient. S.E: Standart Error. P < 0.05:

Statistically significant. Exp (B): Odds Ratio.

A similar comparison of infants over $4000 \mathrm{~g}$ and less than $4000 \mathrm{~g}$ through a regression analysis showed that maternal BMI and vitamin supplementation were important parameters for the prediction of a birth weight over $4000 \mathrm{~g} \quad(\mathrm{p}<0.001$ and $\mathrm{p}=0.044$, respectively).
Vitamin+iron usage increased the risk of a birth weight over $4000 \mathrm{~g} 4.4$ times, but this did not reach statistical significance $(p=0.096)$. Only the use of iron did not increase the risk $(\mathrm{p}=0.654)$ (Table 4$)$.

\section{DISCUSSION}

In this study, the number of newborns over $4000 \mathrm{~g}$ was higher among women using vitamin and vitamin+iron supplementation than the iron group and the control group.

According to present study; in the literature, there is numerous studies demonstrated an increase in birth weight as a result of supplementation with multivitamins. ${ }^{13-15}$ Some studies indicated increased birth weight by multivitamins might enhance the risk of obesity in adults. ${ }^{16}$ In 2015 Dougan et al demonstrated that exposure to prenatal vitamins was not associated with body fatness either in childhood and adulthood. ${ }^{17}$

In this study, we could find no association between iron supplementation and birth weight/macrosomia, although a combination of vitamin+iron lead to increased birth weight. Iron is an important microelement that is essential for expanding the hemoglobin mass during pregnancy, and iron deficiencies are the most widespread, affecting more than 50 percent of all pregnant women in developing countries, and being prevalent also in the industrialized parts of the world. ${ }^{18}$ The treatment of iron deficiencies seems to have a beneficial effect on 
pregnancy outcomes. Milman et al. compared iron-treated pregnant women with placebo-treated pregnant women, and found that the women taking iron had greater iron reserves and higher hemoglobin levels than those taking the placebo during pregnancy and in the postpartum period. ${ }^{19}$ In order to avoid iron deficiency in pregnancy, they advised considering the use of prophylactic iron supplements. Long et al have suggested that an iron deficiency in a low birth-weight premature infant whose mother had taken iron supplementation during their pregnancy was very rare, in that iron supplementation can improve indicators of hematologic iron status and reduce the occurrence of iron deficiencies. ${ }^{20}$

Since 50 percent of pregnant women are deficient in iron, some physicians prefer to administer it prophylactically. Although there is no general recommendation for iron supplementation during pregnancy, serum ferritin levels can be used to identify a need for iron supplements. Suggested guidelines by Milman are "(1) ferritin $>70$ microg/l: no iron supplements; (2) ferritin 30-70 microg/l: $40 \mathrm{mg}$ ferrous iron daily; and (3) ferritin<30 microg/l: 80-100 mg ferrous iron daily". ${ }^{21}$

In this study, it was demonstrated that most influential parameter in birth weight is maternal BMI, after which comes prenatal vitamin supplementation. A high maternal BMI is associated with abnormal fetal growth and fetal macrosomia, and this, it would appear, increases 2- to 3fold in obese pregnant women. ${ }^{22}$ The prevalence of maternal obesity has risen rapidly over the past two decades, with 64 percent of women of reproductive age being overweight and 35 percent obese in the United States. ${ }^{23}$ Maternal obesity might result in macrosomia of fetus due to the abundance of nutrients that also pass to the fetus transplacentally. Insulin resistance which causes high insulin and IGF levels in fetal circulation increases transplacental passage and the deposition of nutrients already found in abundance. Some pregnancy complications related to obesity or maternal overweight such as gestational diabetes, hypertension and preeclampsia can occur and affect fetal growth. ${ }^{24}$

Major limitation of our study is its retrospective design. In addition, regular drug usage was determined by the patient's response only. Because of all tablets contained folic acid, we ignored how folic acid effects on birth weight. The great numbers of participants and statistically homogenous groups are the strengths of our study.

\section{CONCLUSION}

In conclusion, the use of multivitamins and/or iron supplements by pregnant women must take into account maternal age, maternal diet and maternal BMI. Our findings support a reduction in the use of vitamin and iron supplements in pregnancy, and a reversal of the trend to start vitamin and iron supplementation without any control. The increasing prevalence of obesity and excessive weight in pregnant women should be a warning against the uncontrolled usage of vitamins and iron during pregnancy. The unnecessary use of vitamin supplements may carry risks, and can lead to macrosomia and maternal-fetal complications. Numbers needed to treat for specific nutrient deficiencies are unknown, and so individual evaluation is better where possible. There is a distinct lack of well designed, controlled studies in this subject, and new studies with larger samples are needed to confirm and allow a generalization of the results.

Funding: No funding sources

Conflict of interest: None declared

Ethical approval: The study was approved by the Institutional Ethics Committee

\section{REFERENCES}

1. Janna ML, and Regnault RH. "Nutrition in Pregnancy: Optimising Maternal Diet and Fetal Adaptations to Altered Nutrient Supply. 2016;342.

2. Oken E, Ning Y, Rifas-Shiman SL, Rich-Edwards JW, Olsen SF, Gillman MW. Diet during pregnancy and risk of preeclampsia or gestational hypertension. Ann Epidemiol. 2007;17:663-8.

3. Changamire FT, Mwiru RS, Peterson KE, Msamanga GI, Spiegelman D, Petraro P. Effect of multivitamin supplements on weight gain during pregnancy among HIV-negative women in Tanzania. Mat child nutrit. 2015;11:297-304.

4. Zhang Q, Ananth CV, Li Z, Smulian JC. Maternal anaemia and preterm birth: a prospective cohort study. Int J Epidemiol. 2009;38:1380-9.

5. Lee HS, Kim MS, Kim MH, Kim YJ, Kim WY. Iron status and its association with pregnancy outcome in Korean pregnant women. Eur J Clin Nutr. 2006;60: 1130-5.

6. Christian P, Tielsch JM. Evidence for multiple micronutrient effects based on randomized controlled trials and meta-analyses in developing countries. J Nutr. 2012;142:173-7.

7. Ramakrishnan U, Manjrekar R, Rivera J, GonzalesCossio, Martorell R. Micronutrients and pregnancy outcome: a review of the literature. Nutrit Res. 1999; 19: 103-9.

8. Nils Hovdenak N, Haram K. Influence of mineral and vitamin supplements on pregnancy outcome. Eur J Obstet Gynecol Reprod Biol. 2012;164:127-32.

9. George L. Wehby, Eduardo E. Castilla, Jorge S. Lopez-Camelo, Jeffrey C. Murray Predictors of multivitamin use during pregnancy in Brazil. Int $\mathbf{J}$ Public Health. 2009;54:78-87.

10. Blumfield M, Hure A, MacDonald-Wicks L, Smith R, Simpson S, Raubenheimer, D. The association between the macronutrient content of maternal diet and the adequacy of micronutrients during pregnancy in the Women and Their Children's Health (Watch) study. Nutrients. 2012;4(12):1958-76.

11. Watson PE, McDonald BW. The association of maternal diet and dietary supplement intake in 
pregnant New Zealand women with infant birthweight. Eur J Clin Nutr. 2010;64:184-93.

12. Urbaniak T, Klejewski A, Pisarska M, Kostecka E. Influence of dietary supplementation on newborn weight. Przegl Lek. 2012;69:1015-20.

13. Hodgetts VA, Morris RK, Francis A, Gardosi J, Ismail KM. Effectiveness of folic acid supplementation in pregnancy on reducing the risk of small-for-gestational age neonates: a population study, systematic review and meta-analysis. BJOG: An International Journal of Obstetr Gynaecol. 2015;122(4):478-90.

14. Sauder KA, Starling AP, Shapiro AL, Kaar J L, Ringham BM, Glueck DH. Exploring the association between maternal prenatal multivitamin use and early infant growth: The Healthy Start Study. Pediatric obesity; 2015.

15. Haider BA, Bhutta ZA. Multiple-micronutrient supplementation for women during pregnancy. The Cochrane Library; 2012.

16. Yang, Z, Huffman, SL. Nutrition in pregnancy and early childhood and associations with obesity in developing countries. Maternal child nutrition. 2013; $9(\mathrm{~S} 1), 105-19$.

17. Dougan, MM, Willett WC. Michels KB. Prenatal vitamin intake during pregnancy and offspring obesity. Internat J Obesit. 2015;39(1):69-74.

18. WHO Global Database on iron deficiency and anaemia, micronutrient deficiency information system. Iron deficiency anaemia, assessment, prevention, and control. A guide for programme managers. Geneva, World Health Organization; 2001.

19. Milman N, Bergholt T, Byg KE, Eriksen L, Graudal $\mathrm{N}$. Iron status and iron balance during pregnancy. A critical reappraisal of iron supplementation. Acta Obstet Gynecol Scand. 1999;78:749-57.

20. Long H, Yi JM, Hu PL, Li ZB, Qiu WY, Wang F. Benefits of Iron supplementation for low birth weight infants: A systematic review. BMC Pediatr. 2012;12:99.

21. Milman N. Iron prophylaxis in pregnancy--general or individual and in which dose? Ann Hematol. 2006; $85: 821-8$

22. Ehrenberg H, Mercer B, Catalano P. The influence of obesity and diabetes on the prevalence of macrosomia. Am J Obstet Gynecol. 2004;191:964-8.

23. Flegal KM, Carroll MD, Kit BK, Ogden CL. Prevalence of obesity and trends in the distribution of body mass index among US adults, 1999-2010. JAMA 2012;307: 491-7.

24. Tenenbaum-Gavish K, Hod M. Impact of maternal obesity on fetal health. Fetal Diagn Ther. 2013;34:17.

Cite this article as: Kalem MN, Kamalak Z, Kosus N, Kosus A, Kalem Z. Prenatal multivitamin supplementation increases birth weight. Int J Reprod Contracept Obstet Gynecol 2017;6:2148-53. 